\title{
The Characterization of Anti-HER-2/neu Monoclonal Antibody using Different in vivo Imaging Techniques
}

\author{
Cheol Moon ${ }^{1}$, Eun Jung Kim ${ }^{2}$, Dan Bee Choi ${ }^{2}$, Byoung Soo Kim², \\ Sa Hyun Kim ${ }^{1}$ and Tae Hyun Choi ${ }^{2, \dagger}$ \\ ${ }^{1}$ Department of Clinical Laboratory Science, Semyung University, Jecheon 390-711, Korea \\ ${ }^{2}$ Molecular Imaging Research Center, Korea Institute of Radiological and Medical Sciences (KIRAMS), \\ Seoul 139-706, Korea
}

\begin{abstract}
Recently, specific antibodies have been used extensively to diagnose and treat various diseases. It is essential to assess the efficacy and specificity of antibodies, especially the in vivo environment. Anti-HER-2/neu mAb was evaluated as a possible transporting agent for radioimmunotherapy. The monoclonal antibody was successfully radio-labeled with ${ }^{131} \mathrm{I}$. In vitro binding assays were performed to confirm its targeting ability using another radio-iodine, ${ }^{125}$ I. Binding percentage of ${ }^{125} \mathrm{I}$ labeled anti-HER-2/neu mAb in HER-2/neu expressing CT-26 cells was found to be $4.5 \%$, whereas the binding percentage of ${ }^{125} \mathrm{I}$ labeled anti-HER-2/neu mAb in wild-type CT-26 was only $0.45 \%$. In vivo images were obtained and analyzed through $\gamma$-camera and an optical fluorescent modality, IVIS-200. $\gamma$-camera images showed that ${ }^{131} \mathrm{I}$ labeled anti-HER-2/nеu mAb accumulated in HER-2/nеи CT-26 tumors. Optical imaging based on near infrared fluorescence labeled anti-HER-2/neu mAb showed higher fluorescence intensities in HER-2/neu CT-26 tumors than in wild-type CT-26 tumors. Anti-HER-2/neu mAb was found to specifically bind to its receptor expressing tumor. Our study demonstrates that in vivo imaging technique is a useful method for the evaluation of an antibody's therapeutic and diagnostic potentials.
\end{abstract}

Key Words: Radioimmunotherapy (RIT); In vivo imaging; Monoclonal antibody; HER-2/neu oncogene

\section{INTRODUCTION}

Tumor targeting by radiolabeled $\mathrm{mAb}$ is an attractive approach to cancer treatment (Fani et al., 2002). RIT is a form of targeted therapy that uses parent mAbs to deliver radioactivity, which is emitted by a conjugated radioisotope, to antigen positive tissues (Kraeber-Bodéré et al., 2014). Tumor cells are damaged by the combined effects of the antibody and ionizing radiation (Read ED, 2014). Moreover,

\footnotetext{
*Received: February 1, 2015 / Accepted: March 13, 2015

${ }^{\dagger}$ Corresponding author: Tae Hyun Choi. Molecular Imaging Research Center, Korea Institute of Radiological and Medical Sciences (KIRAMS), Seoul 139-706, Korea.

Tel: +82-2-970-1489, Fax: +82-2-970-2435

e-mail: thchoi@kirams.re.kr

(OThe Korean Society for Biomedical Laboratory Sciences. All rights reserved.
}

tumor cells not bound by antibody may still be affected by radiation from adjacent cells, due to cross-fire (Shimoni and Nagler, 2007). During the past few years, the U.S. Food and Drug Administration approved two RIT pharmaceuticals for the treatment of non-Hodgkin's lymphoma, i.e., the antiCD20 monoclonal antibodies, ${ }^{90}$ Y-ibritumomab tiuxetan (Zevalin) and ${ }^{131}$ I-tositumomab (Bexxar). Moreover, several new radioimmunoconjugates are currently being evaluated in clinical trials (Sharkey and Goldenberg, 2005). Therapeutic radionuclides usually emit $\beta$-particles to the tumor (Fani et al., 2002). ${ }^{131}$ I is one of the radionuclides mostly used for RIT (Lewington V, 2005). However, recently, instead of ${ }^{131} \mathrm{I},{ }^{90} \mathrm{Y}$ is used for RIT studies because of pure $\beta$ emission (DeNardo GL, 2000), and its $\beta$ particles penetrate more effectively than ${ }^{131} \mathrm{I}$ (Esteban JM, 1990). However, as ${ }^{90} \mathrm{Y}$ does not emit gamma rays, the in vivo distribution of 
${ }^{90}$ Y-labeled antibody cannot be visualized (Wiseman GA, 2000). Some target antigens (e.g. HER-1, dHER-2/neu) are internalized by cells after antibody binding (Jaramillo et al., 2006). Moreover, ${ }^{90} \mathrm{Y}$ is a radiometal that is retained intracellularly, whereas ${ }^{131} \mathrm{I}$ is released from cells by deiodination (Witzig TE, 2006). ${ }^{186} \mathrm{Re}$ is another metallic radionuclide suitable for RIT. It emits both $\beta$ and $\gamma$ radiation. These $\gamma$ rays, which are emitted in only $9 \%$ of the disintegrations, are of low energy (137 keV) whereas $\beta$ emissions are of medium energy (mean $362 \mathrm{keV}$ ) (van Gog FB et al., 1997). ${ }^{67} \mathrm{Cu}$ is also a possibility for RIT and provides low energy $\beta$ emissions (average $141 \mathrm{keV}$ ) and medium energy gamma rays $(185 \mathrm{keV})$ which are suitable for imaging (DeNardo et al., 1999).

Members of the receptor tyrosine kinase family, which include epidermal growth factor receptor (EGFR), ErbB-2/ HER-2, ErbB-3/HER-3, and ErbB-4/HER-4, have frequently been implicated in experimental models of epithelial cell neoplasia in animals and in humans (Rajkumar and Gullick, 1994; Glenney 1992; Kroese et al., 2007; Porter and Vaillancourt, 1998). Moreover, many mAb products have been approved for clinical use in United states, and more are currently under clinical evaluation (Adams and Weiner, 2005). The Her-2/neu gene encodes a $185 \mathrm{kDa}$ transmembrane protein that is a member of the type I family of growth factor receptors (Akiyama et al., 1986; Bargmann, 1986). Amplification of this gene results in the overexpression of a $185-\mathrm{kDa}$ receptor tyrosine kinase which is homologous to EGF3 receptor (Coussens et al., 1985; Stern et al., 1986; Kraus et al., 1987). However, unlike EGF receptor, which binds many known ligands, no direct ligand of HER-2/neu has been reported (Hurwitz et al., 1995).

MAb to HER-2/neu (Trastuzumab/Herceptin) has been approved by the Federal Drug Administration (FDA) for the treatment of tumors that express high levels of HER-2/ $n e u$, and herceptin has a good therapeutic effect. However, recently, combined therapies, such as, antibody and chemotherapy, antibody and radio therapy (RIT) are being studies (Pfeiffer et al., 2007).

Molecular imaging can be defined as the in vivo characterization and measurement of biologic processes at the cellular and molecular levels (Massoud and Gambhir, 2003).
The strategy of molecular imaging involves the use of unique molecular probes that target specific molecules, such as, receptors, transporters, or enzymes (Sakiyama et al., 2007; Shikano et al., 2007; Alattia et al., 2007). Moreover, specificities of such interactions, delivery pharmacokinetics, and the signal-to-noise ratio of molecular probes can be characterized by molecular imaging. However, the development and validation of specific molecules is time-consuming and requires significant effort, and thus these advantages of molecular imaging are important for evaluating the specificities of potential delivery systems (Gunn et al., 2007).

In vitro and in vivo antibody developments are required for RIT because the biodistribution of the radioconjugated antibody and its targeting ability should be confirmed. Nowadays, antibody development studies are performed by small animal imaging, because small animal imaging enables accurate quantification, the localizations of biological processes and events, new developed antibodies to be characterized before human studies, and because it provides near perfectly registered images which improve interpretation and quantification (Jacobs and Cherry, 2001).

Here, we report our evaluation of the merits of antiHER-2/neu antibody based on small animal imaging. Our study provides information about the in vivo characteristics of anti-HER-2/neu mAb and provides supportive pre-clinical data for clinical applications.

\section{MATERIALS AND METHODS}

\section{Materials}

Erbitux (Cetuximab) was purchased from Merck Inc. (Germany), Herceptin (Trastuzumab) from Roche Inc. (USA), and IRDye $800 \mathrm{CW}$ from Li-Cor Inc. (USA). Fluorescein isothiocyanate (FITC), IODO-Bead and desalting dextran column were obtained from pierce (USA) and Vivaspin 500 from Vivagen (Germany). ${ }^{125}$ I was from Perkin Elmer (USA), and ${ }^{131}$ I from the Korean Atomic Energy Research Institute (KAERI, Korea). Phosphate buffered saline ( $\mathrm{pH}$ 7.4; $0.01 \mathrm{~mol} / \mathrm{l})$, Dulbecco's phosphate buffered saline ( $\mathrm{pH}$ 7.4) and casein blocker were purchased from Biorad (USA). 


\section{Preparation of radioiodine labeled antibody}

Iodination of the antibody was accomplished using IodoBeads. A single Iodo-Bead was washed with $0.5 \mathrm{ml}$ of 0.2 $\mathrm{mol} / \mathrm{l}$ phosphate buffer ( $\mathrm{pH}$ 6.5) and dried on filter paper, and then placed in an eppendorf tube $1 \mathrm{mCi}$ of radioiodine and an equal volume of $0.2 \mathrm{~mol} / \mathrm{l}$ phosphate buffer $(\mathrm{pH}$ 6.5) was added, incubated for 15 minutes at room temperature $\left(25^{\circ} \mathrm{C}\right) .200 \mu \mathrm{g}$ of antibody was then added and incubation continued for 30 minutes at room temperature $\left(25^{\circ} \mathrm{C}\right)$. The reaction was terminated by removing the Iodo-Bead. Labeling yield was determined by radio thin layer chromatography using silica coated glass and acetone as a developing solution.

\section{Labeling of antibody with near-infrared fluorescence IRDye 800CW}

IRDye 800CW fluorescent conjugates have an absorption maximum at $774 \mathrm{~nm}$ and an emission maximum of $789 \mathrm{~nm}$ in $1 \mathrm{X}$ PBS. IRDye $800 \mathrm{CW}$ dye bears a NHS ester reactive group that couple to primary amines on the antibody. IRDye $800 \mathrm{CW}$ ( $0.1 \mathrm{mg}$ for $1 \mathrm{mg}$ of protein) was dissolved in $50 \mu \mathrm{l}$ of DMSO (Sigma, USA), $1 \mathrm{mg}$ of antibody was added, and incubated overnight at $4{ }^{\circ} \mathrm{C}$ in the dark. The reaction mixture was then passed through a desalting dextran column (Pierce, USA) eluted and with $0.01 \mathrm{~mol} / 1$ phosphate buffered saline ( $\mathrm{pH}$ 7.4) (Biorad, USA). Fractions were concentrated by ultracentrifugation (Beckman Coulter, USA), and the product so obtained was diluted in PBS to a concentration of $1 \mathrm{mg} / \mathrm{ml}$ and stored in the dark at $-20^{\circ} \mathrm{C}$ until required.

\section{Cell line and cell culture}

Mouse colorectal adenocarcinoma CT-26 and HER-2/ neu CT-26 cells were obtained from the Laboratory of Immunology at Seoul National University. CT-26 and HER-2/neu CT-26 cells were maintained as monolayer cultures in DMEM supplemented with $10 \%$ fetal bovine serum, $100 \mathrm{units} / \mathrm{ml}$ penicillin, and $100 \mu \mathrm{g} / \mathrm{ml}$ streptomycin in a humidified $5 \% \mathrm{CO}_{2}$ atmosphere at $37^{\circ} \mathrm{C}$.

\section{In vitro binding test}

All steps in the antibody binding assay were done at $4{ }^{\circ} \mathrm{C}$. Cells were washed 3 times with D-PBS (PBS (pH 7.4) without $\mathrm{CaCl}_{2}$ and $\mathrm{MgCl}_{2}$ ). $1 \times 10^{6}$ cells were counted and incubated for $1 \mathrm{~h}$ with ${ }^{125}$ I-labeled antibody with or without a 100-fold molar excess cold antibody, and then washed twice with casein blocker. Radioisotope was counted using a Wallac 1470 gamma counter (Wallac, Finland). To correct for radioactive decay, standards were counted simultaneously.

\section{Experimental animal model}

6- to 8-week-old female athymic nude mice (BALB/c-nu Slc, Japan) were housed five/cage and provide sterilized water. Tumor cells were harvested near confluence by incubation with $0.05 \%$ trypsin-EDTA. Cells were pelleted by centrifugation at $1,500 \mathrm{rpm}$ for 3 minutes and then resuspended in serum free media. Cells $\left(2 \sim 3 \times 10^{6} /\right.$ animal $)$ were implanted subcutaneous into the thighs of mice. Tumors reached roughly $1 \mathrm{~cm}$ in size after 4 weeks.

\section{Gamma camera images of radiolabeled antibody in small animal models}

To obtain gamma camera images, mice were injected via a tail vein with radioisotope labeled antibody. Briefly, a mouse was anesthetized with $2 \%$ isoflurane and placed gamma camera (DIACAM; Siemens, Germany). Images were acquired for $1 \times 10^{6}$ counts using a $4 \mathrm{~mm}$ pin-hole. Data was stored in a $512 \times 512$ pixel matrix using a digital computer and processed using a special color display without background subtraction or interpolation.

\section{Longitudinal fluorescence optical imaging of live mice and image processing}

Live animal fluorescence optical imaging was performed using the IVIS 200 (Xenogen, USA). Imaging parameters were selected and implemented using on-board Living Image 2.5 software. An ICG excitation and emission filter was used with an excitation band of $710 \mathrm{~nm}$ to $760 \mathrm{~nm}$ and a emission band of $810 \mathrm{~nm}$ to $875 \mathrm{~nm}$. Bright field photographs were obtained in each case. Images were obtained 


\begin{tabular}{lrrrrrrrr} 
& $\begin{array}{r}(\mathrm{mm}) \\
\text { Reg }\end{array}$ & $\begin{array}{l}(\mathrm{mm}) \\
\text { Start }\end{array}$ & $\begin{array}{r}(\mathrm{mm}) \\
\text { Stop }\end{array}$ & $\begin{array}{l}\text { Centroid } \\
\text { RF }\end{array}$ & $\begin{array}{r}\text { Region } \\
\text { Counts }\end{array}$ & $\begin{array}{r}\text { Region } \\
\text { CPM }\end{array}$ & $\begin{array}{r}\% \text { of } \\
\text { Total }\end{array}$ & $\begin{array}{r}\% \text { of } \\
\text { ROI }\end{array}$ \\
\hline Rgn 1 & 1.1 & 20.3 & 10.0 & 0.167 & 107375.0 & 107375.0 & 94.05 & 97.73 \\
Rgn 2 & 36.9 & 56.1 & 44.3 & 0.738 & 2409.0 & 2409.0 & 2.11 & 2.19 \\
Bkg 1 & 73.5 & 83.1 & 77.7 & 1.294 & & & & \\
Rgn 3 & 89.2 & 96.2 & 92.5 & 1.541 & 86.0 & 86.0 & 0.08 & 0.08 \\
\hline \multicolumn{2}{l}{ 3 Peaks } & & & & 109870.0 & 109870.0 & 96.23 & 100.00
\end{tabular}

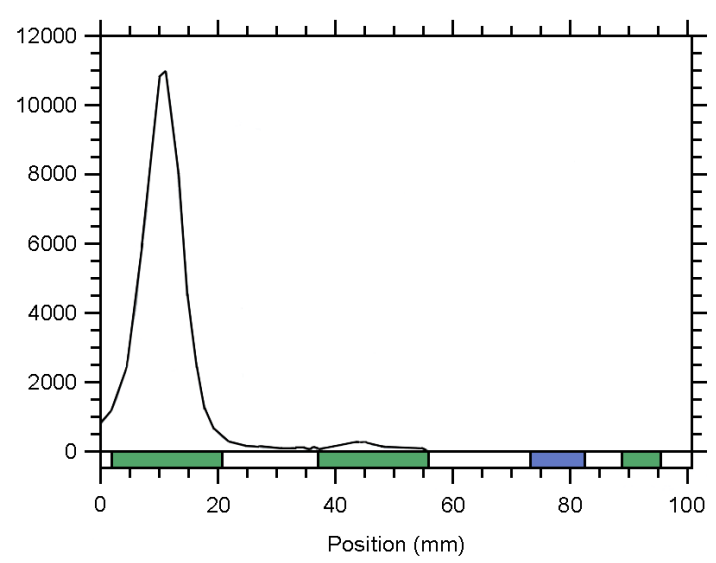

Fig. 1. Labeling efficiency of anti-HER $2 /$ neu antibody with ${ }^{131} \mathrm{I}$, measured by thin layer chromatography (TLC). The labeling mixture containing antibodies, radioisotopes and chemicals were migrated on the silica coated glass buffered by acetone. Anti-HER2/neu antibodies were labeled with ${ }^{131} \mathrm{I}$, demonstrating about $94 \%$ of labeling efficiency.

in posterior and anterior views. Because near infrared fluorescence is susceptible with light, mouse were kept in dark room.

\section{RESULTS}

\section{Evaluation of anti-HER2/neu mAb for radiolabeling}

We assessed whether the anti-HER2/neu antibody could be labeled with the radioisotope. ${ }^{131}$ I was used for the radiolabeling test with Iodo-bead system. The labeling efficiency was measured by radio thin layer chromatography with acetone as a developing buffer. About $94 \%$ of antibody was radiolabeled with ${ }^{131} \mathrm{I}$ (Fig. 1). This result demonstrates that the anti-HER2/neu antibody is suitable for radiolabeling with ${ }^{131} \mathrm{I}$ and suggests that the experiment of in vivo $\gamma$-camera imaging would be possible with the antibody after radio-labeling.

\section{In vitro binding assays using anti-HER-2/neu mAb}

To evaluate expressions of HER-2/neu antigens in HER-2

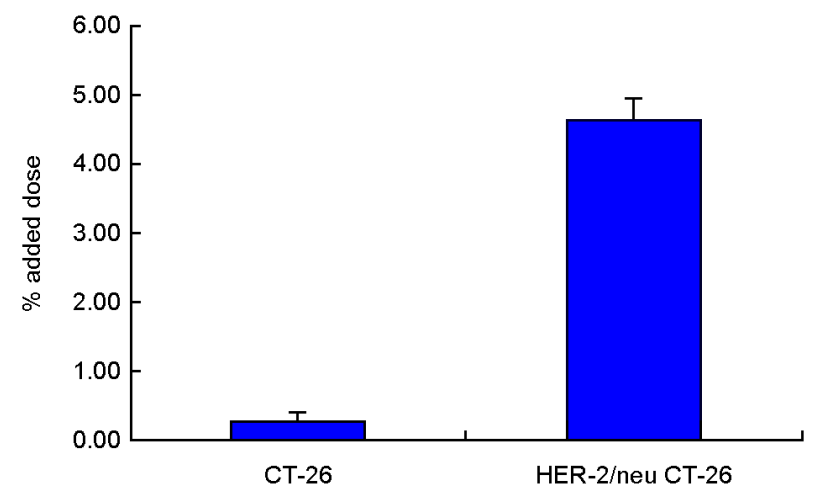

Fig. 2. In vitro binding assay of HER-2/neu CT-26 and wild-type CT-26 cell lines. Expression of HER-2/neu antigen is higher in HER-2/neu CT-26 than in wild-type CT-26. Binding \% was 4.64 $( \pm 0.64)$ for HER-2/neu CT-26 and $0.26( \pm 0.29)$ for wild-type CT-26. The experiment was repeated two times.

Ineu CT-26 and wild-type CT-26 cells, in vitro cell binding assays were performed (Fig. 2). Anti-HER-2/neu mAb was labeled with ${ }^{125} \mathrm{I} .{ }^{125} \mathrm{I}$ - anti-HER-2/neu $\mathrm{mAb}$ was bound to 1 $\times 10^{6}$ cells of each cell line. The binding percentage of added doses of antibody was determined by gamma counter analysis. This experiment was repeated two times. More than 20 times of radioactivity remained in HER-2/neu CT-26 compared to wild-type CT26. 4.64\% $( \pm 0.64)$ of added dose is measured with HER-2/neu CT-26 and 0.26 ( \pm 0.29 ) with wild-type CT-26. In this study, we determined that HER-2/neu CT-26 cells possessed more antigens than wild-type CT-26.

\section{Gamma camera imaging using ${ }^{131}$ I-anti-HER-2/neu mAb}

Then, we assessed the in vivo characteristics of antiHER-2/neu antibodies with xenotransplanted mouse cancer model. HER-2/neu CT-26 and wild-type CT26 were injected in athymic nude mouse: HER-2/neu CT-26 in the right thigh and wild-type CT26 in the left. $200 \mu \mathrm{Ci}$ of ${ }^{131} \mathrm{I}$ radiolabeled anti-HER-2/neu antibody were administrated intravenously and gamma camera images of the mouse were obtained at indicated time points after antibody injection; $1 \mathrm{~h}$, $3 \mathrm{~h}, 20 \mathrm{~h}, 24 \mathrm{~h}$ and $48 \mathrm{~h}$ (Fig. 2). After $3 \mathrm{~h}$ of injection, the accumulation of ${ }^{131}$ I-radiolabeled anti-HER-2/neu antibody appeared at the right thigh implanted HER-2/neu CT26 and increased until $48 \mathrm{~h}$ after injection. However, there was no 
signal of accumulation of radio labeled antibody at wildtype CT26 implanted region until $24 \mathrm{~h}$, although a slight increase of signal was observed at $48 \mathrm{~h}$. These results show that in vivo gamma camera imaging could be possible with radio-labeled anti-HER-2/neu monoclonal antibody as the antibody binds preferentially to HER-2/neu antigen expressed tumor even in vivo.

\section{Near infrared optical imaging using IRDye 800CW- anti-HER-2/neu mAb}

Next, we evaluate the potential use of anti-HER-2/neu antibody for in vivo fluorescence imaging. We chose a near infrared fluorechrome, IRDye $800 \mathrm{CW}$, which has an emission wavelength of $794 \mathrm{~nm}$. Anti-HER-2/neu antibody was conjugated to the near infrared fluorescence and injected into a mouse bearing HER-2/neu CT26 tumor and wild-type CT26 tumor. Following anesthetization with $2 \%$ isoflurane, the mice were scanned using the IVIS 200 at various time points. The obtained images were constructed and normalized with Living image 3D software. At the time point of $1 \mathrm{~h}$, the signals started appearing in either tumor regions,

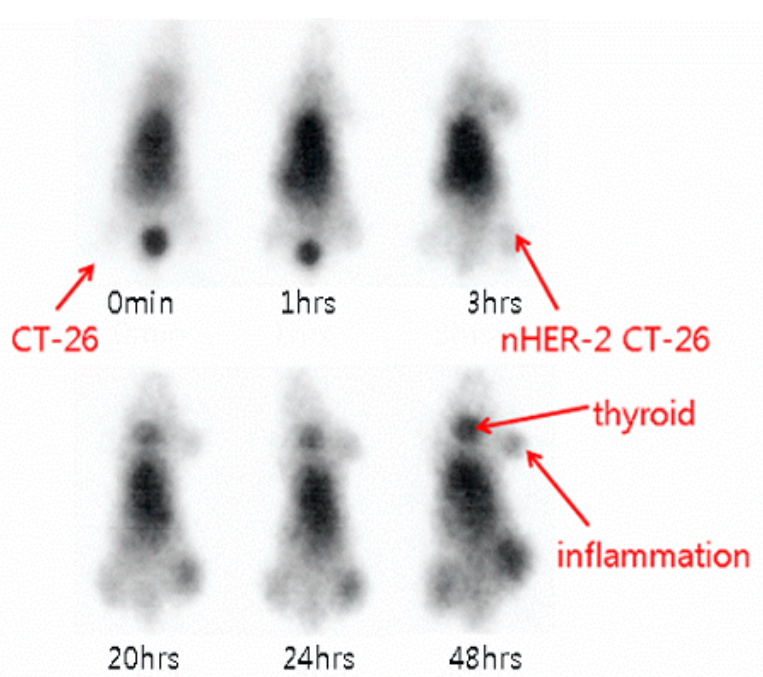

Fig. 3. Gamma camera image of tumor bearing animal model. The left thigh contained a wild-type CT-26 tumor and the right thigh a HER-2/neu CT-26 tumor. Anti-HER-2/neu mAb was labeled with ${ }^{131}$ I. The image was obtained using a $4 \mathrm{~mm}$ pin-hole and a $512 \times$ 512 matrix. At 20 h p.i., ${ }^{131}$ I-anti-HER-2/neu mAb accumulated in the HER-2/neu CT-26 tumor region, and with time, radioactivity in the HER-2/neu CT-26 tumor region became more increased than in the wild-type CT-26 tumor region. even slightly higher level in wild-type CT26 tumor region, and more obvious fluorescent signals appeared in either tumor regions at $3 \mathrm{~h}$, and these simultaneous signals were maintained and enhanced until $24 \mathrm{~h}$. However, at $48 \mathrm{~h}$, the signal of wild-type CT26 tumor diminished, while that of

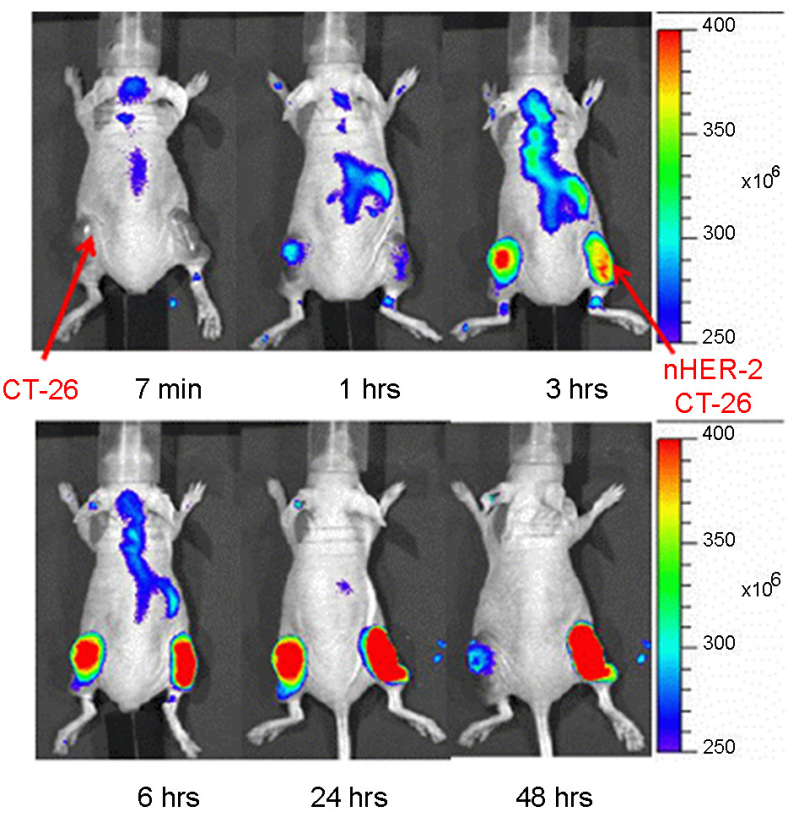

Fig. 4. Direct comparison of near infrared fluorescence imaging of HER-2/neu CT-26 and wild-type CT-26. Anti-HER-2/neu mAb was labeled with IRDye $800 \mathrm{CW}$, near infrared fluorescence dye. Each image was normalized by Living 3D image software. Image was acquired from $7 \mathrm{~min}$ to $48 \mathrm{~h}$ p.i.

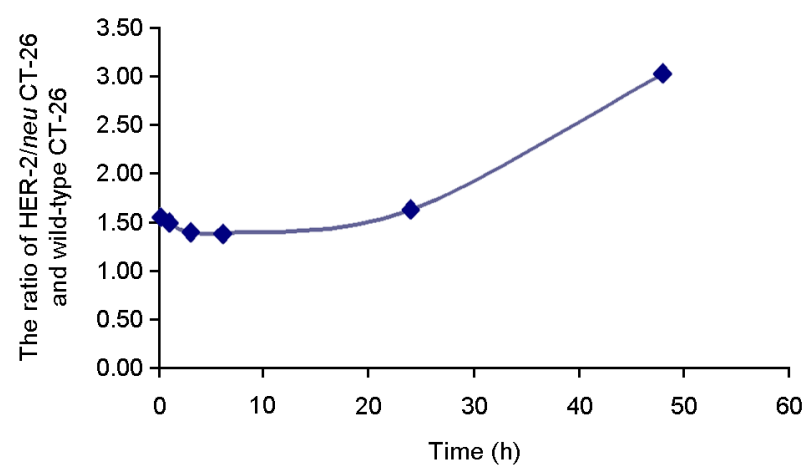

Fig. 5. HER-2/neu CT-26 to wild-type CT-26 ratios in near infrared fluorescence images. ROIs were drawn in tumor region using the Living Image 3D program. The HER-2/neu CT-26 to wild-type CT-26 ratio was 1.56 at $5 \mathrm{~min}$ and 3.04 at $48 \mathrm{~h}$, and this ratio rapidly increased at $24 \mathrm{~h} p . i$. 
HER-2/neu CT26 tumor persisted. The ratio of fluorescent signal between the regions of HER-2/neu CT-26 and wildtype CT-26 by ROI analysis of tumor region are shown in Fig. 5. HER-2/neu CT-26 and wild-type CT-26 ratios clearly increased from 1.56 at $5 \mathrm{~min}$ p.i. to 3.04 at $48 \mathrm{~h} \mathrm{p.i.,}$ indicating the preferential binding of IRDye $800 \mathrm{CW}$-antiHER-2/neu antibody to HER-2/neu CT-26 tumor.

\section{DISCUSSION}

A cancer specific marker (or antigen) is an important element for the characterization of cancer and the development of cancer treatment modality. Despite the complexities of the nature of cancer specific markers, targeting a cancer specific marker being expressed on the surface of cancer by a specific ligand, could allow diagnosing a stage of cancer and providing treatment methods. Especially, the cancer specific markers could be used for in vivo imaging. Patients with breast cancer that overexpress HER-2/neu have a significantly lower survival rate and a shorter time to relapse (Slamon et al., 1987). Also, high levels of HER-2/neu expression have been positively correlated with lymph node metastasis in breast cancer (Lacroix et al., 1989; Tan et al., 1997). Some studies have suggested that high level HER-2/ neu expressions are positively correlated with resistance to certain anti-cancer drugs and radiation-therapies (Yu et al., 1998; Arteaga et al., 1994).

The radioimmunotherapy (RIT) is a good example of treatment using cancer specific marker. RIT is a form of targeted therapy that uses parent mAbs to deliver radioactivity, which is emitted by a conjugated radioisotope, to antigen positive tissues (Kraeber-Bodéré et al., 2014). Tumor cells are damaged by the combined effects of the antibody and ionizing radiation (Read et al., 2014). During the past years, the U.S. Food and Drug Administration approved two RIT pharmaceuticals for the treatment of non-Hodgkin's lymphoma, i.e., the anti-CD20 monoclonal antibodies, ${ }^{90}$ Y-ibritumomab tiuxetan (Zevalin) and ${ }^{131}$ I-tositumomab (Bexxar). Moreover, several new radioimmunoconjugates are currently being evaluated in clinical trials (Sharkey and Goldenberg, 2005). The monoclonal antibody to HER-2/neu, Trastuzumab/Herceptin, has been approved by Federal Drug Administration (FDA) for the treatment of tumors that express high levels of HER-2/neu and it has a good therapeutic effect. However, combined therapies, such as, antibody and chemotherapy, antibody and radio therapy (RIT) have been studied (Pfeiffer et al., 2007).

In order to evaluate the potential use of HER-2/neu antigen and its ligand anti-HER-2/neu $\mathrm{mAb}$ for in vivo imaging, we studied in vivo and in vitro characteristics of an anti-HER-2/neu monoclonal antibody. First of all, we tested if the anti-HER-2/neu antibody can be labeled with radioisotopes. Iodo-bead method was used for preparing radioiodine labeled antibody. As seen in Fig. 1, the antibody was successfully labeled with ${ }^{131}$ I and the labeling efficiency was $94 \%$ after thin layer chromatography (TLC) verification. Then, the binding ability of radiolabeled antibody to HER-2/ neu antigen was tested. The HER-2/neu expressing cancer cell line, HER-2/neu CT26 was incubated with ${ }^{125}$ I-labeled antibody, and after washing, the remaining radioactivity was measured by using a gamma counter. More than 20 times of radioactivity are measured with HER-2/neu expressing CT26, compared to control cell line, CT26 (Fig. 2). Although it was not possible to show statistical meaning, because of

Table 1. The nuclear properties of radioiodine isotopes

\begin{tabular}{lcll}
\hline \hline Radio nuclide & Physycal half life & \multicolumn{1}{c}{$\begin{array}{c}\text { Mode of decay } \\
\text { (gamma Energy) }\end{array}$} & Possible application \\
\hline I-123 & 13.2 hours & Electron capture $(159 \mathrm{KeV})$ & Imaging (SPECT) \\
I-124 & 4.2 days & Beta $+(511 \mathrm{KeV})$ & Imaging (PET) \\
I-125 & 60 days & Electron capture $(\mathrm{X}$ ray: $34 \mathrm{KeV})$ & In vitro and imaging \\
I-131 & 8 days & Beta $-(364 \mathrm{KeV})$ (Beta rays for therapy) & Imaging (SPECT), therapy \\
\hline
\end{tabular}

SPECT $=$ Single Photon Emisstion Computed Tomography, Gamma Camera $\mathrm{PET}=$ Positron Emission Tomography 
Table 2. Spectral properties of representative fluorescence dyes

\begin{tabular}{lccl}
\hline \hline Fluorescence dye & Excitation wavelength & Emission wavelength & Possible application \\
\hline FITC & $493 \mathrm{~nm}$ & $518 \mathrm{~nm}$ & In vitro \\
Texas Red & $593 \mathrm{~nm}$ & $618 \mathrm{~nm}$ & In vitro \\
Cy 5.5 & $692 \mathrm{~nm}$ & $712 \mathrm{~nm}$ & In vitro and In vivo \\
ICG (IRdye 800) & $777 \mathrm{~nm}$ & $794 \mathrm{~nm}$ & In vitro and In vivo \\
\hline
\end{tabular}

a limitation of experiments, this result could demonstrate that the radiolabeled antibody is able to interact specifically with HER-2/neu antigen. We have used 2 different radioiodines to verify if antibody labeling is influenced by different type of radioiodines. The antibody was successfully labeled with two different radioiodines with almost same efficacy (data not shown). As described in Table 1, there are various types of radioiodine that can be used according to needs. ${ }^{124} \mathrm{I}$ is used for PET (positron emission tomography) imaging and kinetic modeling evaluations because it emits positrons, whereas ${ }^{131} \mathrm{I}$ emits the gamma-photons and $\beta$-particles, which allow it to be used for imaging and therapy (Buchsbaum et al., 1993; Kaminski et al., 1992). It seems to be important to verify if an antibody could be labeled with various probes. Since anti-HER-2/neu antibody is feasible for labeling with radio-iodine and fluorescent probes, two modalities of in vivo imaging could be used.

The in vivo specific targeting of anti-HER-2/neu mAb was tested through the radio- and fluorescent imaging. Consistent with in vitro findings, specific targeting of ${ }^{131} \mathrm{I}$ anti-HER-2/neu mAb to HER-2/neu antigen was demonstrated in tumor bearing animal model (Fig. 3). The gamma camera images of mice bearing HER-2/neu CT-26 tumors and wild-type CT-26 tumors demonstrated that the accumulations of ${ }^{131}$ I were obvious in HER-2/neu CT-26 tumors but not in wild type tumors (Fig. 3). Uptake ratios between HER-2/neu CT-26 and CT-26 (HER-2/neu CT-26 to CT-26) started to increase slightly at the time point of $3 \mathrm{~h}$. This increase was clearer at $20 \mathrm{~h}$ and maximized at $48 \mathrm{~h}$ (Fig. 3). Also, HER-2/neu CT-26 specific antibody binding was tested with in vivo fluorescent images. Specific binding of IRDye $800 \mathrm{CW}$ (a near infrared fluorescing dye) labeled antiHER-2/neu mAb showed markedly more fluorescence at HER-2/neu expressing tumor than the wild-type tumor (Fig.
4). Since the fluorchromes with short emission wavelength, FITC, Texas Red, have some limitations for in vivo imaging, IRDye $800 \mathrm{CW}$ was used. This near infrared flourchrome has a longer emission wavelength even than Cy5.5, which is generally used for in vivo imaging with an emission wavelength of $712 \mathrm{~nm}$ (Table 2). As expected, significant fluorescent signals appeared at $3 \mathrm{~h}$ after antibody injection in the both tumors, even, wild type tumor showed a stronger signal. But, after $6 \mathrm{~h}$, strong fluorescent signals appeared at HER-2/neu expressing tumor. This signal pattern continued until $48 \mathrm{~h}$, where the wild type tumor signals were clearly decreased at $48 \mathrm{~h}$ time point. The increase of signal ratio of HER-2/neu CT-26 to CT-26 is more clearly demonstrated in Fig. 5, indicating preferential binding of IRDye $800 \mathrm{CW}$ anti-HER-2/neu antibody to HER-2/neu CT-26 tumor. With all these in vivo imaging data, we could visually analyze the specific biodistribution of the injected antibody. Also, it is important to note that the increased localization of antibodies in HER-2/neu CT-26 region about $24 \mathrm{~h}$ after injection was observed even by 2 different imaging modalities. This may indicate that the localization of antibodies we observed was a real in vivo behavior of the antibody. In conclusion, our study demonstrates and confirms clearly that in vivo imaging technique is suitable for this purpose, as we characterized anti-HER-2/neu antibody.

\section{Acknowledgements}

This study was supported by the Semyung University Research Grant of 2012.

\section{REFERENCES}

Adams GP, Weiner LM. Monoclonal antibody therapy of cancer. Nat Biotechnol. 2005. 23: 1147-1157. 
Akiyama T, Sudo C, Ogawara H, Toyoshima K, Yamamoto T. The product of the human c-erbB-2 gene: a 185-kilodalton glycoprotein with tyrosine kinase activity. Science. 1986. 232: 1644-1646.

Alattia JR, Shaw JE, Yip CM, Privé GG. Molecular imaging of membrane interfaces reveals mode of beta-glucosidase activation by saposin C. Proc Natl Acad Sci U S A. 2007. 104: 17394-17399.

Arteaga CL, Winnier AR, Poirier MC, Lopez-Larraza DM, Shawver LK, Hurd SD, Stewart SJ. p185c-erbB-2 signal enhances cisplatin-induced cytotoxicity in human breast carcinoma cells: association between an oncogenic receptor tyrosine kinase and drug-induced DNA repair. Cancer Res. 1994. 54: 3758 -3765 .

Bargmann CI, Hung MC, Weinberg RA. The neu oncogene encodes an epidermal growth factor receptor-related protein. Nature. 1986. 319: 226-230.

Buchsbaum DJ, Langmuir VK, Wessels BW. Experimental radioimmunotherapy. Med Phys. 1993. 20: 551-567.

Coussens L, Yang-Feng TL, Liao YC, Chen E, Gray A, McGrath J, Seeburg PH, Libermann TA, Schlessinger J, Francke U, Levinson A, Axel Ullrich. Tyrosine kinase receptor with extensive homology to EGF receptor shares chromosomal location with neu oncogene. Science. 1985. 230: 1132-1139.

Crawford LM Jr. From the Food and Drug Administration. JAMA. 2002. 288: 1579 .

DeNardo GL, DeNardo SJ, O'Donnell RT, Kroger LA, Kukis DL, Meares CF, Goldstein DS, Shen S. Are radiometal-labeled antibodies better than iodine-131-labeled antibodies: comparative pharmacokinetics and dosimetry of copper-67-, iodine131-, and yttrium-90-labeled Lym-1 antibody in patients with non-Hodgkin's lymphoma. Clin Lymphoma. 2000. 1: 118-126.

DeNardo GL, Kukis DL, Shen S, DeNardo DA, Meares CF, DeNardo SJ. ${ }^{67} \mathrm{Cu}$-versus ${ }^{131}$ I-labeled Lym-1 antibody: comparative pharmacokinetics and dosimetry in patients with non-Hodgkin's lymphoma. Clin Cancer Res. 1999. 5: 533-541.

Esteban JM, Hyams DM, Beatty BG, Merchant B, Beatty JD.

Radioimmunotherapy of human colon carcinomatosis xenograft with ${ }^{90}$ Y-ZCE025 monoclonal antibody: toxicity and tumor phenotype studies. Cancer Res. 1990. 50: 989s-992s.

Fani M, Vranjes S, Archimandritis SC, Potamianos S, Xanthopoulos S, Bouziotis P, Varvarigou AD. Labeling of monoclonal antibodies with ${ }^{153} \mathrm{Sm}$ for potential use in radioimmunotherapy. Appl Radiat Isot. 2002. 57: 665-674.

Glenney JR Jr. Tyrosine-phosphorylated proteins: mediators of signal transduction from the tyrosine kinases. Biochim Biophys Acta. 1992. 1134: 113-127.

Gunn AJ, Brechbiel MW, Choyke PL. The emerging role of molecular imaging and targeted therapeutics in peritoneal carcinomatosis. Expert Opin Drug Deliv. 2007. 4: 389-402.

Hurwitz E, Stancovski I, Sela M, Yarden Y. Suppression and promotion of tumor growth by monoclonal antibodies to ErbB-2 differentially correlate with cellular uptake. Proc Natl Acad Sci U S A. 1995. 92: 3353-3357.

Jacobs RE, Cherry SR. Complementary emerging techniques: highresolution PET and MRI. Curr Opin Neurobiol. 2001. 11: 621 $-629$.

Jaramillo ML, Leon Z, Grothe S, Paul-Roc B, Abulrob A, O'Connor McCourt M. Effect of the anti-receptor ligand-blocking 225 monoclonal antibody on EGF receptor endocytosis and sorting. Exp Cell Res. 2006. 312: 2778-2790.

Kaminski MS, Fig LM, Zasadny KR, Koral KF, DelRosario RB, Francis IR, Hanson CA, Normolle DP, Mudgett E, Liu CP, Moon S, Scott P, Miller RA, Wahl RL. Imaging, dosimetry, and radioimmunotherapy with iodine 131-labeled anti-CD37 antibody in B-cell lymphoma. J Clin Oncol. 1992. 10: 1696 -1711 .

Kraeber-Bodéré F, Bodet-Milin C, Rousseau C, Eugène T, Pallardy A, Frampas E, Carlier T, Ferrer L, Gaschet J, Davodeau F, Gestin JF, Faivre-Chauvet A, Barbet J, Chérel M. Radioimmunoconjugates for the treatment of cancer. Semin Oncol. 2014. 41: 613-622.

Krose M, Zimmern RL, Pinder SE. HER2 status in breast cancer--an example of pharmacogenetic testing. J R Soc Med. 2007. 100: 326-329.

Kraus MH, Popescu NC, Amsbaugh SC, King CR. Overexpression of the EGF receptor-related proto-oncogene erbB-2 in human mammary tumor cell lines by different molecular mechanisms. EMBO J. 1987. 6: 605-610.

Lacroix H, Iglehart JD, Skinner MA, Kraus MH. Overexpression of erbB-2 or EGF receptor proteins present in early stage mammary carcinoma is detected simultaneously in matched primary tumors and regional metastases. Oncogene. 1989. 4: 145-151.

Lewington V. Development of ${ }^{131}$ I-tositumomab. Semin Oncol. 2005. 32: S50-S56.

Massoud TF, Gambhir SS. Molecular imaging in living subjects seeing fundamental biological processes in a new light. Genes Dev. 2003. 17: 545-580.

Pfeiffer P, Nielsen D, Yilmaz M, Iversen A, Vejlø C, Jensen BV. 
Cetuximab and irinotecan as third line therapy in patients with advanced colorectal cancer after failure of irinotecan, oxaliplatin and 5-fluorouracil. Acta Oncol. 2007. 46: 697-701.

Porter AC, Vaillancourt RR. Tyrosine kinase receptor-activated signal transduction pathways which lead to oncogenesis. Oncogene. 1998. 17: 1343-1352.

Rajkumar T, Gullick WJ. The type I growth factor receptors in human breast cancer. Breast Cancer Res Treat. 1994. 29: 3-9.

Read ED, Eu P, Little PJ, Piva TJ. The status of radioimmunotherapy in CD20+ non-Hodgkin's lymphoma. Target Oncol. 2015. 10: 15-26.

Richman CM, DeNardo SJ. Systemic radiotherapy in metastatic breast cancer using ${ }^{90}$ Y-linked monoclonal MUC-1 antibodies. Crit Rev Oncol Hematol. 2001. 38: 25-35.

Sakiyama Y, Hatano K, Tajima T, Kato T, Kawasumi Y, Suzuki M, Ito $\mathrm{K}$. An atlas-based image registration method for dopamine receptor imaging with PET in rats. Ann Nucl Med. 2007. 21: 455-462.

Sharkey RM, Goldenberg DM. Perspectives on cancer therapy with radiolabeled monoclonal antibodies. J Nucl Med. 2005. 46: 115-127.

Shikano N, Nakajima S, Kotani T, Ogura M, Sagara J, Iwamura Y, Yoshimoto M, Kubota N, Ishikawa N, Kawai K. Transport of D-[1-14C]-amino acids into Chinese hamster ovary (CHO-K1) cells: implications for use of labeled d-amino acids as molecular imaging agents. Nucl Med Biol. 2007. 34: 659-665.

Shimoni A, Nagler A. Radioimmunotherapy and stem-cell transplantation in the treatment of aggressive B-cell lymphoma. Leuk Lymphoma. 2007. 48: 2110-2120.
Slamon DJ, Clark GM, Wong SG, Levin WJ, Ullrich A, McGuire WL. Human breast cancer: correlation of relapse and survival with amplification of the HER-2/neu oncogene. Science. 1987. 235: 177-182.

Stern DF, Heffernan PA, Weinberg RA. p185, a product of the neu proto-oncogene, is a receptorlike protein associated with tyrosine kinase activity. Mol Cell Biol. 1986. 6: 1729-1740.

Tan M, Yao J, Yu D. Overexpression of the c-erbB-2 gene enhanced intrinsic metastasis potential in human breast cancer cells without increasing their transformation abilities. Cancer Res. 1997. 57: 1199-1205.

van Gog FB, Visser GW, Stroomer JW, Roos JC, Snow GB, van Dongen GA. High dose rhenium-186-labeling of monoclonal antibodies for clinical application: pitfalls and solutions. Cancer. 1997. 80: 2360-2370.

Wiseman GA, White CA, Stabin M, Dunn WL, Erwin W, Dahlbom M, Raubitschek A, Karvelis K, Schultheiss T, Witzig TE, Belanger R, Spies S, Silverman DH, Berlfein JR, Ding E, Grillo-López AJ. Phase I/II ${ }^{90} \mathrm{Y}-Z$ evalin (yttrium-90 ibritumomab tiuxetan, IDEC-Y2B8) radioimmunotherapy dosimetry results in relapsed or refractory non-Hodgkin's lymphoma. Eur J Nucl Med. 2000. 27: 766-777.

Witzig TE. Radioimmunotherapy for B-cell non-Hodgkin lymphoma. Best Pract Res Clin Haematol. 2006. 19: 655-668.

Yu D, Liu B, Jing T, Sun D, Price JE, Singletary SE, Ibrahim N, Hortobagyi GN, Hung MC. Overexpression of both p185cerbB2 and p170mdr-1 renders breast cancer cells highly resistant to taxol. Oncogene. 1998. 16: 2087-2094. 